\title{
Economic Natural Laws and Economics
}

\author{
Yi-Jang Yu \\ Department of Economics, Ming-Chuan University, Taoyuan County, Taiwan \\ Email: vivu@mail.mcu.edu.tw
}

Received 2 December 2014; revised 20 December 2014; accepted 30 December 2014

Copyright (C) 2015 by author and Scientific Research Publishing Inc.

This work is licensed under the Creative Commons Attribution International License (CC BY).

http://creativecommons.org/licenses/by/4.0/

c) (i) Open Access

\begin{abstract}
Human activity causes extensive destruction to nature. However, nature is necessary to us; continuing to damage it regardless of consequence is unwise. Microeconomic and macroeconomic natural laws were introduced by [1], but the global economy is not operating in compliance with the microeconomic natural law. If ignorance of the importance and feasibility of the microeconomic natural law is the reason for the global economy to not adhere to it, then more explanations must be provided. The current mainstream school of economics has already resolved the threat of resource scarcity; therefore, reinforcing the shortage of this school is necessary to undertake the new mission of addressing the threat of environmental destruction.
\end{abstract}

\section{Keywords}

Economic, Microeconomic Natural Law, Macroeconomic Natural Law, Threat of Environmental Destruction

\section{Introduction}

Human activity causes extensive destruction to nature. However, nature is necessary to us; continuing to damage it regardless of consequence is unwise. Microeconomic and macroeconomic natural laws were introduced by [1], but the global economy is not operating in compliance with the microeconomic natural law. If ignorance of the importance and feasibility of the microeconomic natural law is the reason for the global economy to not adhere to it, then more explanations must be provided.

Concepts and analytical methods of mainstream economics have been criticized to be incompetent in explaining how the economic world operates and in predicting its future. One of the major problems is believed to be the lack of aggressiveness in emphasizing the important implications of uncertainty and risk. Based on Markowitz's portfolio theory (MPT) [2] and the Capital Asset Pricing Model (CAPM) [3], the financial market developed a standardized method of quantifying risk. Since then, related ideas have never been widely accepted in mainstream economics. This involved a controversy between positive and normative economics; currently, nor- 
mative economics is preferred because in addition to scarcity, relation and risk are also major factors in the dynamic economic world, and they can only be analysed in normative ways [4]. Moreover, without a world government, worldwide consensus and cooperation for resolving the threat of environmental destruction must rely on ethics.

The second major problem is the inability to endogenise environmental factors in pricing models; instead, they are treated as only sources of externalities. Our ecosystem has already been substantially damaged, but the focus of debate remains on assigning blame and identifying the culprit instead of endogenising environmental factors ${ }^{1}$.

The third major problem is the difficulty to include moral factors in economic analyses; excluding such factors is against the trend of economic development. If the problem of scarcity has been effectively solved and the primary interest of world economic development is in ethics, then we would be irrational to remain fixated on materialism [6].

The final major problem is the avoidance of discussing the ultimate goal of human life but focusing only on the fulfillment of short-term demands. Although defining this goal is not easy, we can still form meaningful abstract inferences and become less narrow-minded in the way we live. For example, the understanding of this ultimate goal may enable us to acknowledge that, with respect to future generations, even individual economic behaviour must take responsibility for environmental sustainability ${ }^{2}$.

The foundation of economics must be reformed to enable the effective restoration of destructed environments. This can begin with recognising the importance of microeconomic and macroeconomic natural laws; the pace of world economic development can then be stabilised and progress towards achieving the meaning of human life.

\section{Microeconomic Natural Law}

Reference [1] proposed that when relation and risk factors are combined and applied to the MPT, the pricing model for real goods is

$$
\tilde{r}_{i}=\beta_{1} \tilde{R}_{g}+\beta_{2} \tilde{R}_{c}+\beta_{3} \tilde{R}_{i}+\varepsilon_{i}
$$

For any economic entity $i$, the market growth rate $\tilde{r}_{i}$ is linked to three supply variables including $\tilde{R}_{g}$ as the real growth rate of its system variable, $\tilde{R}_{c}$ as the real growth rate of its complements or substitutes, and $\tilde{R}_{i}$ as the real growth rate with respect to $\tilde{r}_{i}$. With the system variable $\tilde{R}_{g}$, the sum of all three coefficients is a strict relationship of

$$
\hat{\beta}_{1}+\hat{\beta}_{2}+\hat{\beta}_{3}=1
$$

Regarding financial assets that have high degrees of homogeneity, the asset pricing model according to [8] is

$$
\tilde{r}_{i}=\beta_{1} \tilde{R}_{g}+\beta_{2} \tilde{R}_{i}+\varepsilon_{i}
$$

Again, the sum of both coefficients equals one. This is because the inclusion of the system variable $\tilde{R}_{g}$ causes the covariance between $\tilde{R}_{g}$ and $\tilde{R}_{i}$ to be exactly equal to the variance of $\tilde{R}_{g}$, hence ensuring that the sum of both coefficients is one.

\subsection{Effectiveness}

As the mainstream asset pricing model, the CAPM is a univariate model, which exogenises the system or the economic environment variable $\tilde{R}_{g}$ and replaces the real variable $\tilde{R}_{i}$ with a market portfolio variable $\tilde{r}_{m}$ in Equation $(3)^{3}$. Because the coefficient of $\tilde{r}_{m}$ has no other balancing force, it may be excessively inflated by

\footnotetext{
1“Although natural scientists serve as the leading informants of ecological problems, they are not well equipped to explain a very basic puzzle. How could such a widespread set of dire ecological problems-which nobody intended and nobody wants-emerge and persist, despite a massive increase in international environmental awareness and regulation over the past forty years? Some environmentalists have a simple answer to this puzzle: 'It's globalization, stupid!'” [5].

"'We are living in a society in which individuals and group constantly appeal to rights against others without recognizing any responsibilities of their own.” [7].

${ }^{3}$ According to [8], if $\tilde{R}_{i}$ is excluded from the model, the direct link to the basic analysis will be completely blocked.
} 
manipulation unless the system variable $\tilde{r}_{g}$, which is the market variable of $\tilde{R}_{g}$, is included ${ }^{4}$. However, this bivariate model characterised by market features serves only the job of discounting uncertain future values [8].

To solve Equation (3), individual and systematic risks must be first identified to reveal the required system variable. This differs substantially from the traditional way of model-building in positive economics, especially because the system variable is unknown unless the environment can reach a significant degree of risk diversification.

However, although both ecological and social environments cannot be directly included in the pricing model, the economic environment can be included. Because the system variable can be produced automatically in Equations (1) and (3), the spirit of free market is not violated. In addition, based on the balancing mechanism of all explanatory variables, the effect of market stabilisation can be guaranteed. Finally, individual fate is affected by two independent forces of which one can be controlled and the other cannot. Therefore, Equations (1) and (3) are not unscientific when they can incorporate all the aforementioned features.

\subsection{Practicality}

Industrial structure or competition intensity can be studied based on the structural relation expressed in Equation (2). Moreover, the two-dimensional rule of performance evaluation introduced in [8] can be applied because this relation can be treated as weights with a sum of one. After incorporating the environment variable that represents the opportunity of development, the most objective system of performance evaluation can be established ${ }^{5}$.

Evidently, the microeconomic natural law cannot exist without an available system variable; this reflects the importance of governmental association especially at the initial stage of industrial development. According to [9], in order to reveal the systematic risk, the number of participants must not be less than 15. Therefore, the government should promote new industries to diversify the nation's industrial structure, and encourage new participants to achieve a significant degree of diversification within each industry. Only after that can the stability of the environment for national economic development be realised. If the government intends to further reduce the systematic risk of the national economy, it can accomplish this through international cooperation in trade and economy. However, according to MPT, reducing systematic risk always has a limit.

The economic development of a country usually results in too many industries; hence, the outcome approaches the minimum-risk portfolio instead of the optimal portfolio. This is how perfect competition would occur in a two-dimensional risk-return world; the arrangement of optimal allocation of resources is never the case. Moreover, for a multinational company or even the European Union, the difference between the minimum-risk and optimal portfolios can provide important insights on whether having too many participants is favorable.

Regarding the development of expertise, creation of more job opportunities, and establishment of competitive advantage, another important question is how one nation can design its own effective policy for industrial development. First, no single nation can dominate all industries; therefore, quality of industries should be the focus instead of quantity. Second, standard industrial classification can change from two-digits to three-digits and more, which means that there is substantial opportunity for development. When the expertise of every link within the industrial chain is established, more synergy in expertise between the links can be achieved to strengthen the competitive advantage in industrial development.

\section{Macroeconomic Natural Law}

The economic world is a part of nature. Therefore, logical thinking based on careful observation of the nature should be applicable for analysing the vicissitude of global economic development. According to the $I$ Ching, two eternal forces, Yin and Yan, cyclically affect the world. In the terms of the economy, Yin means preparation, restoration and other digressive contents, whereas Yan means production, creation and other aggressive contents. Moreover, according to the Five-element Doctrine, each cycle dominated by Yin or Yan can be divided into five

\footnotetext{
${ }^{4}$ If the beta's correlation coefficient of the CAPM is greater than 0 , the asset risk and pricing result can be directly and positively correlated. ${ }^{5} \mathrm{By}$ using the traditional market portfolio $m$ to represent the opportunity of development in the environment and the WINDEX (S) introduced by [8] as the basis of evaluation, changes in $\Delta S_{m-i}$, which equals $S_{m}-S_{i}$, can thus be used to evaluate the performance of every identity $i$ within the environment. If $\Delta S_{m-i}$ increases, even if $\Delta S_{i}$ can also increase, the performance of $i$ remains poor because more opportunities provided by the environment cannot be effectively mastered by $i$; by contrast, if $\Delta S_{m-i}$ is decreasing, then even if $\Delta S_{i}$ is negative, the performance is still favourable because it has a strong ability to resist stress.
} 
different stages that generate, in the natural order, the elements of fire, earth, metal, water, and wood; this order is then repeated in the next cycle.

The first five-element cycle of economic development ended recently. Because resource scarcity was the primary threat to human life, the primary economic mission in that cycle was to effectively resolve this threat. During the process of resolving the threat, human wisdom led the world from the fire stage, which represents the acquisition economy, to the earth stage, which represents the pastoral economy, in order to obtain certain control of risk. Subsequently and occasionally, the abundance of subsistence goods could be too serious to cause an economic threat. After trials-and-errors, the common solution was eventually to upgrade subsistence goods to make necessities. Hence, the world economy entered the metal stage, which represents the manufacturing economy. When the surplus of necessities would cause a new economic threat, the immediate solution was to create new markets; hence, the cycle entered the water stage, which represents the commercial economy that primarily includes the logistics and finance industries. Globalisation therefore became the ultimate strategy of obtaining economies of scale. When this strategy was no longer feasible, increasing added values of necessities was considered. Eventually, the transformation of necessities into luxuries became a common solution, and information and knowledge management of consumer preferences became the trend, moving the economic world into the current stage of wood, which represents the knowledge economy.

The direct solution to the threat of resource scarcity must be active creation and production. However, if productivity increases continuously, both threat and effect of resolving the threat will become marginally reduced, eventually reaching a level of insignificance. Several scholars have declared that the threat of resource scarcity has already been resolved [6] [10]. After the industrial revolution, over consumption has damaged the environment enough to threaten human life. In order to restore the environment, the first five-element cycle of economic development, which is characterised by aggressiveness and construction, therefore must be replaced by the second cycle, which is characterised by digressiveness and repair. Moreover, the primary mission of the second cycle is to repair the environment, and it must start with the earth stage to repair the ecological environment which is already in an urgent condition. Afterwards, the cycle will enter the metal and water stages to repair the economic environment, and finally, will enter the wood stage to repair the social environment.

Without substantial interference, the threat of environmental destruction will gradually diminish during the second five-element cycle of economic development. However, this may not occur if the microeconomic natural law remains ignored in the world; the microeconomic natural law is the natural way to stop further environmental destruction [4].

\subsection{Effectiveness}

In addition to the element-generating relationships, the concept of Five Elements also has element-overcoming relationships. In order, this starts from fire overcoming metal, to metal overcoming wood, to wood overcoming earth, to earth overcoming water, to water overcoming fire of the next cycle, and so on. The wood stage in the first five-element cycle of economic development can overcome the earth stage, or the ecological environment, of the second cycle. This means that excessive development of the knowledge economy in the first cycle will damage the ecological environment in the second cycle. This is because individual rationality has already been excessively exerted in the first cycle; further advancement by the power of knowledge that focuses only on individual desires will accelerate environmental destruction.

Unless the microeconomic natural law becomes universally accepted, the macroeconomic natural law will eventually be destroyed. This is because, if environmental factors remain treated as exogenous variables, the consequence of integrating individual rationality with the power of knowledge will be the further encouragement of over-consumption of resources, hence exacerbating environmental destruction. In other words, the effective operation of the macroeconomic natural law depends entirely on the support from the microeconomic natural law.

\subsection{Practicality}

Examining the first five-element cycle of economic development revealed that the path of global economic development is abrupt and destined, starting from the acquisition to the pastoral, manufacturing, commerce, and finally the present knowledge economy. The driving force behind this path is the continuous eradication of new 
threats to human life, which by nature also has a purpose ${ }^{6}$. When one threat is eradicated, another threat will emerge. Although our short-term purpose seems to be the continuous advance of human wisdom to improve our ability to confront new challenges, our long-term purpose must be to achieve the ultimate goal of human life.

Nature advocates following the trend because this conforms to the principle of cost-benefit analysis. Opposing the trend creates problems to the economic development of a nation. For example, before the metal stage or manufacturing economy can be realised and the surplus of necessities become substantial enough to cause an economic threat, excessive construction of transportation facilities and expansion of financial markets will misallocate resources and hinder real economic development. Moreover, if the development plan skipped stages and progressed from the earth stage or the pastoral economy immediately to the wood stage or the knowledge economy, the entire society will likely favour knowledge-based jobs and despise labour-intensive jobs that have the lowest added values, and the threat of food shortage may increase as a consequence [1].

\section{Ethics and Learning}

To resolve the threat of resource scarcity in the first five-element cycle of economic development, economic growth can be the answer. However, because the primary mission in the second cycle is to solve the problem caused by environmental destruction, development of ethics is the answer. In fact, the discussion of ethics has never ceased in the entire human history. The only problem is that emphasising ethics too early without sufficient support from the society is ineffective.

For the society as a whole, individual rationality can have positive or negative effects; hence, it must be guided with incentives or penalties in order for people to work for virtue. However, material incentives can only have a marginally decreasing effect and no mechanism of penalty can cause people to happily oblige; therefore, only general ethics can be relied on. According to [12], "we presently lack even the conception of a General Ethics.” At the beginning of the second five-element cycle of economic development, all nations should exert more effort in the education of general ethics. This is also one of the tasks that should be achieved during the fire stage of the second cycle, in addition to discovering new energy sources and generating new ideas of resource consumption.

Similar to the first five-element cycle of economic development, the second cycle will also start from the fire stage, but will now rely on curtesy instead of material incentive to produce wise ideas regarding energy sources and resource consumption. Examples of using the concept of curtesy instead of material rewards to invite external assistance were described in Wikinomics [13].

In the second cycle, after the fire stage is the earth stage and the new mission is to repair the ecological environment. However, before the existence of a global government, all national governments can only rely on trust to reach consensus and avoid the problem of free-riders [14]. According to the Five Elements, trust is the foundation for establishing other general ethics required in the subsequent stages. To repair the metal stage or the manufacturing economic environment, justice will be primarily relied on to terminate the production of goods and services that are not environmentally sustainable. To repair the water stage or the financial economic environment, wisdom will be relied on to understand the financial market and reduce the appeal of speculation and malpractice. Subsequently, benevolence will be relied on to repair the social environment.

However, even if the era of ethics has arrived, precaution is still necessary. "For ethics, too, cannot be had without conflict." [7]. After the end of the first five-element cycle of economic development, knowledge became the basic tool for repairing environments in the next cycle, but general ethics will be primarily relied on to accomplish the economic missions in this cycle. Similarly, at the end of the second cycle, benevolence will become the basic element for managing the new threat to human life, but what will be relied on remains unknown. Based on the Yinattributes accompanying the second cycle, the new threat must be spiritual in nature ${ }^{7}$. This means finding the solution may require studying the field of metaphysics.

\subsection{Competition and Cooperation}

Competition or cooperation has been a topic of long dispute in economics, and involves even the debate between

\footnotetext{
${ }^{6}$ “The capacity to manage risk, and with it the appetite to take risk and make forward-looking choices, are key elements of the energy that drives the economic system forward.” [11].

${ }^{7}$ At the end of the second five-element cycle of economic development, the new threat to human life may be caused by wars of religion [4]. Reference [7] once mentioned, "[r]igious become irreconcilable when they exaggerate the differences and keep silent about what is held in common. In this way conflicts can become total, to the point of collective self-destruction.”
} 
capitalism and socialism. First, cooperation means trading a certain degree of autonomy for coordination. Individual demands can be either immediate or future demands; the tradeoff for satisfying immediate (or future) demands is the fulfillment of future (or immediate) demands. Therefore, each person competes with people in the present and people of the future-generation for scarce resources. During the first five-element cycle of economic development, human beings learned to exercise competitive cooperation to hunt large animals or plunder more effectively ${ }^{8}$. Eventually, tribes or countries were formed, and the primary purpose was to maximise the satisfaction of individual desires ${ }^{9}$. However, after the threat of environmental destruction emerged, the necessity of adding certain responsibilities to economic behaviour has shaped global cooperation in the second five-element cycle of economic development, and the repair of global ecology became the primary focus.

Although competition is important for attaining individual free will, too much competition causes misallocation and waste of resources. More losers in competition must mean more waste of resources. Furthermore, with respect to return and risk, and based on MPT, if an industry is close to the condition of perfect competition, it must be close to the minimum-risk portfolio of this industry, which is far from the optimal portfolio of resource allocation (market portfolio).

Furthermore, components of systematic risk are usually not controllable by every participant in the environment unless the limitations of geographic confinement can be overcome by market expansion. In addition, if the government intends to provide its industries and corporations an even more stable environment for development, it can establish trade or economic cooperation with other nations to reduce the systematic risk of the national economy. The higher degree of heterogeneity in economic development the allied nation can have, the higher the reduction of systematic risk after cooperation ${ }^{10}$.

Finally, the more freedom a market has the more diversified outcomes it can have. However, according to MPT, for a less developed nation, after reaching its limit of risk diversification in economic development, what could be affected must be an increase of deviation, and the consequence might be a distortion of the trend of economic development. For a highly developed nation, because its opportunities of increasing its growth rates would have been exhausted, its expected rate of economic development will gradually move leftward. One of the solutions is to form alliances with less developed nations to offset the loss of opportunities for higher growth rates.

\subsection{Opportunity Cost and Ethic}

Empirical studies have been concluded that the great majority of human affair shave a lognormal instead of normal distribution [16]. This implies that the development of human culture is progressing and optimistic in general. However, human destructive force seems limitless and its irrational impact can be hard to imagine. Similar to regulating individual social behavior by implementing laws, establishing constraints in economic behaviour to protect environments or achieve a targeted economic growth rate is necessary. For the economic growth rate, this type of constraints can be expressed as an opportunity cost of development.

After transforming all the opportunities of economic growth into the logarithmic measures based on the hypothesis of lognormal distribution, a bell-shaped diagram can be applied for the following discussion. For a nation that has already exploited most of its opportunities for economic growth, its expected mean growth rate will gradually move leftward. The direct solution is to provide economic stimulation that can create sufficiently high growth rates. Forming foreign alliances and implementing risk control policies are other options. By setting an opportunity cost on the left-hand side of the bell-shaped diagram as a threshold, the area lost on the right-hand side can be balanced by the restriction. However, this type of policy will violate the spirit of economic freedom. The other alternative, as explained by [17], is to lower the systematic risk to obtain a result similar to directly pursuing a high growth rate. As mentioned previously, in practice, the nation should form alliances with other nations that are as heterogeneous as possible in economic development.

Before general ethics can be globally realised and human beings become autonomous, whenever the external costs of certain behaviour cannot be controlled, the behaviour should be completely prohibited regardless of how scientific it is claimed to be. This is because the power of knowledge can have a positive or negative effect. Without full assurance, conservatism is thus required to avoid unnecessary risk. This is especially important for

\footnotetext{
${ }^{8}$ Without cooperation, human beings cannot be strong because our ancestors were relatively smaller and weaker than other species such as the Cro-Magnon.

9“Cooperation was first used, not for virtues reasons, but as a tool to achieve selfish result.” [15].

${ }^{10}$ Therefore, even highly industrialized countries can always consider less industrialised countries as partners for economic cooperation.
} 
the second five-element cycle of economic development when the primary mission is to repair the damaged environment but not to pursue economic growth.

Finally, the environment has to be sustainable; consuming resources without consideration for the future is unwise. However, if all or some exogenous costs are forcefully endogenised, the effectiveness of implementation may be low and the exertion of individual freedom will be hindered accordingly. If the economic environment factor can be automatically endogenised through the microeconomic natural law and the outcome can clearly enhance market stability, then there should be no reason to reject this law. In addition, since the needed economic environment factor must be a standardised system variable, it can thus be used to represent the opportunity cost of the environment. In contrast to the traditional risk-free rate, within the analytical framework of return and risk, new opportunity cost can be more practical for job performance evaluation, especially in non-financial markets.

\section{Normative Analyses}

Positive analyses can involve measures of deviation or standard deviation; however, they have to be performed with the assumption that all things are equal. These types of analyses consider total risk as a fixed or predictable value. However, total risks measured from different economic identities are highly heterogeneous products that are not mutually comparable.

According to [9], if the sample size is too small, the condition of risk diversification will not be satisfied and the systematic risk of the environment will not be revealed. By contrast, if the sample size is too large, although the systematic risk component will be quantifiable, the individual risk component will remain unquantifiable when it varies among objects. Therefore, the present method to quantify an individual risk component is to deduct the systematic risk component from the total risk [8]. Although this normative approach differs substantially from the positive approaches, it is probably the only way to reveal the microeconomic natural law [1].

In the economic world, risks are heterogeneous products and are not mutually comparable. The Sharpe ratios for two different objects $i$ and $j$ can be expressed as $S_{i}$, which is equal to $\left(E_{i}-r_{f}\right) / \sigma_{i}$, and $S_{j}$, which is equal to $\left(E_{j}-r_{f}\right) / \sigma_{j}$. However, since the ratio of the individual and the systematic risk components in $\sigma_{i}$ or $\sigma_{j}$ can differ, and the connotation of each individual risk component can also vary, both $S_{i}$ and $S_{j}$ are not mutually comparable unless they are transformed into a form of WINDEX [8].

Normative analyses can be practical and scientific. As can be demonstrated in Equations (1) and (3), after automatically including an economic environment variable, both models can be constructed to have a powerful balancing and stabilising effect. Moreover, all coefficients in the model can be simplified into a linear relationship with a sum that equals one. As mentioned in Section 2.1, a person's fate depends partially on self-effort and partially on fortune; any pricing model that can conform to this common sense should not be considered unscientific.

Traditionally, the primary element in economic analyses is scarcity. When it is necessary to consider relation and risk factors, only MPT with normative attributes can conduct the standardised analysis. Moreover, the fact that general ethics have become the primary requirement for resolving the threat of environmental destruction emphasises the importance of conducting normative analyses.

\section{The Ultimate Goal of Human Life}

Learning without a goal can only enable the pursuit of pleasure. Having a goal can conform economic behaviour to the economic natural law and hence the decree of economics. Ethics should also have a goal. For example, the power of knowledge can have a positive or negative effect; its use must be guided by general ethics to pursue virtuousness. Moreover, a totally free market cannot be effectively managed by individual morality. This is because one person rarely has the ability and motivation to know whether he or she has over-consumed resources and reduced environmental sustainability.

Similar to the concept of the ecological system proposed by [18], the economic system that is studied without a particular goal is a closed one and equilibrium may be defined. By contrast, every open system must have some parts that are affected exogenously. Without endogenising those exogenous factors, any conclusion of systematic equilibrium could be biased. Human desires are unlimited, and they are contained in an open system. According to A. H. Maslow, when the threat of resource scarcity is reduced substantially, people will pursue mental and spiritual fulfillment. Therefore, freedom of choice in the market should not be the ultimate goal of 
human life ${ }^{11}$.

The evolution of life on earth must have a goal [18]. For human life, the goal has been considered as the pursuit of freedom [10] or the pursuit of joy [19]. The goal cannot be confined to the scope of maximising the satisfaction of individual desires. This is because without a sustainable environment, even the short-term goal of maximising individual desires cannot be accomplished. Therefore, before the ultimate goal of human life is determined, maintaining and enhancing environmental sustainability should be considered as a workable goal with immediate urgency.

\section{Conclusions}

Individual life is limited, but the meaning of life must be immeasurable, otherwise life is meaningless. Nature requires sustainable management. Therefore, avoiding of environmentally unsustainable human activities is natural. Based on these understandings, continuous collective learning to cooperatively resolve physical, economic and environmental threats throughout the economic history can thus be considered as having a substantial meaning; that is, to pursue the ultimate goal of human life.

In the past, numerous religious masters or sages would always remind people that true freedom of life can only be achieved after escaping from material and spiritual dependencies. However, the majority of people cannot understand this without learning from painful experiences. This learning process is inevitable and is a part of the macroeconomic natural law, which continues to function well. However, the destructive force of human beings is seemingly unlimited. No balancing force can be provided by the microeconomic natural law, which has for a long time been ignored. Our destructive power has already damaged the environment to a degree that may ruin the macroeconomic natural law.

People living in different time and space must compete for environmental resources. Threat of resource scarcity therefore originates from individuals, and individual rationality must be exerted to resolve this threat. Even if collective cooperation is exercised, its initial purpose is still to maximise the fulfillment of individual desires. After substantially reducing the threat of resource scarcity, human beings are now confronted with a new threat from environmental destruction. This new threat can only be effectively coped with by the complete cooperation of all national governments. The relevance between competition and cooperation is thus starting to change and lean toward collective cooperation. As a consequence, globalisation and global cooperation are necessary.

Promoting economic development by individual rationality has caused people to consume excessively, which led to the threat of environmental destruction. This is not a counterattack from nature; it is an inevitable error that resulted from the ignorance that came with the effort of resolving the threat of resource scarcity. This should be considered as a lesson from nature, otherwise similar errors will reoccur in the future. Because the primary mission in the current or the second five-element cycle of economic development is to repair destroyed environments, and because ethics rather than materials are the primary requirement, a new threat may emerge from spiritual and moral commonalities, and religious wars may occur.

Although the current global economic development follows the destined path revealed by the macroeconomic natural law, the ignorance towards the microeconomic natural law has caused substantial threats to both the environment and macroeconomic natural law. Unless both microeconomic and macroeconomic natural laws are complementary in operation, the primary mission in the second five-element cycle of economic development cannot be accomplished. Providing that the nature is necessarily depended on, adhering to economic natural laws must be the least resistant and most cost effective than other ways of economic development that do not adhere to the economic natural laws.

Regarding economics, the current mainstream school of economics has already resolved the threat of resource scarcity; therefore, reinforcing the shortage of this school is necessary to undertake the new mission of addressing the threat of environmental destruction. Subsequently, in response to the new threat that will emerge at the end of the second five-element cycle of economic development, economists must identify the new threat and then search for the solution in the field of metaphysics. Ancient wisdom will therefore eventually resume its importance. At present, even if the ultimate goal of human life cannot be defined, a practical economic goal of environmental sustainability can still be clearly expressed in economics textbooks with the purpose of providing equal opportunities to pursue the ultimate goal of human life for every generation.

\footnotetext{
11“'Therefore, it is very much a 'market choice', or indeed 'consumer choice', the freedom of choice that a free-market laissez-faire economy is supposed to intrinsically promote-as opposed to the morally valuable concept of freedom as individual autonomy or self-determination.” [20].
} 
Regarding the destiny of human beings, after abundance prevailed over scarcity in the first five-element cycle of economic development, what accumulated were not materials but knowledge. This is the arrangement of nature; knowledge is the basic tool for repairing the destroyed environment in the second cycle, and hence it has become the fortune of human beings. Similarly, general ethics will be applied to surmount the threat of environmental destruction in the second cycle. However, nature cannot generously provide our world the fortune of general ethics if we completely ignore the microeconomic natural law. Following nature is not unimaginable; we only need to allow the microeconomic natural law to function naturally.

\section{References}

[1] Yu, Y. (2014) A More Practical Method for Explaining Equilibrium. Research in World Economy, 5, 88-98. http://dx.doi.org/10.5430/rwe.v5n1p88

[2] Markowitz, H.M. (1959) Portfolio Selection: Efficient Diversification of Investments. Wiley, New York.

[3] Sharpe, W.F. (1964) Capital Asset Prices: A Theory of Market Equilibrium under Conditions of Risk. Journal of Finance, 19, 425-442. http://dx.doi.org/10.2307/2977928

[4] Yu, Y. (2014) Relations, Risks, Portfolio Theory and Key Natural Laws in Economics. Research in World Economy, 5, 143-149. http://dx.doi.org/10.5430/rwe.v5n2p143

[5] Christoff, P. and Eckersley, R. (2013) Globalization \& the Environment. Rowan \& Littlefield, Lanham

[6] Gailbraith, J.K. (1960) The Affluent Society. College Edition, Riverside, Cambridge.

[7] Küng, H. (1997) A Global Ethic for Global Politics and Economics. Oxford University Press, London.

[8] Yu, Y. (2012) The Asset Pricing System. Modern Economy, 3, 473-480. http://dx.doi.org/10.4236/me.2012.35062

[9] Fama, F.F. (1976) Foundations of Finance. Basic, New York.

[10] Sen, A. (1999) Development as Freedom. Oxford University Press, New York.

[11] Bernstein, P.L. (1998) Against the Gods: The Remarkable Story of Risk. John Wiley \& Sons, New York.

[12] Fox, W. (2006) A Theory of Ethics. MIT, Cambridge.

[13] Tapscott, D. and Williams, A.D. (2006) Wikinomics: How Mass Collaboration Changes Everything. Portfolio, New York.

[14] Colquitt, J.A., LePine, J.A., Piccolo, R.F., Zapate, C.P. and Rich, B.L. (2012) Explaining the Justice-Performance Relationship: Trust as Exchange Deepener or Trust as Uncertainty Reducer? Journal of Applied Psychology, 97, 1-15. http://dx.doi.org/10.1037/a0025208

[15] Ridley, M. (1998) The Origin of Virtue: Human Instincts and the Evolution of Cooperation. Penguin, New York.

[16] Limpert, E., Stahel, W.A. and Abbt, M. (2001) Log-Normal Distribution across the Sciences: Keys and Clues. BioScience, 51, 341-352. http://dx.doi.org/10.1641/0006-3568(2001)051[0341:LNDATS]2.0.CO;2

[17] Yu, Y.J. (2013) A More Practical Method for Explaining Supply. Research in World Economy, 4, 76-81. http://dx.doi.org/10.5430/rwe.v4n1p76

[18] Loasby, B.J. (1991) Equilibrium and Evolution: An Exploration of Connecting Principles in Economics. Manchester University Press, Manchester.

[19] Graham, G. (2011) Theories of Ethics. Routledge, New York.

[20] Lunati, M.T. (1997) Ethical Issues in Economics: From Altruism to Cooperation to Equity. Macmillan, London. http://dx.doi.org/10.1057/9780230373587 
Scientific Research Publishing (SCIRP) is one of the largest Open Access journal publishers. It is currently publishing more than 200 open access, online, peer-reviewed journals covering a wide range of academic disciplines. SCIRP serves the worldwide academic communities and contributes to the progress and application of science with its publication.

Other selected journals from SCIRP are listed as below. Submit your manuscript to us via either submit@scirp.org or Online Submission Portal.
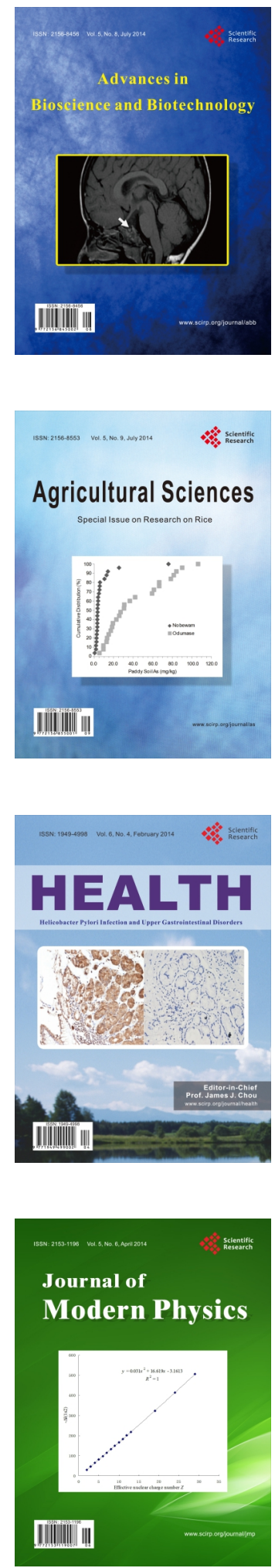
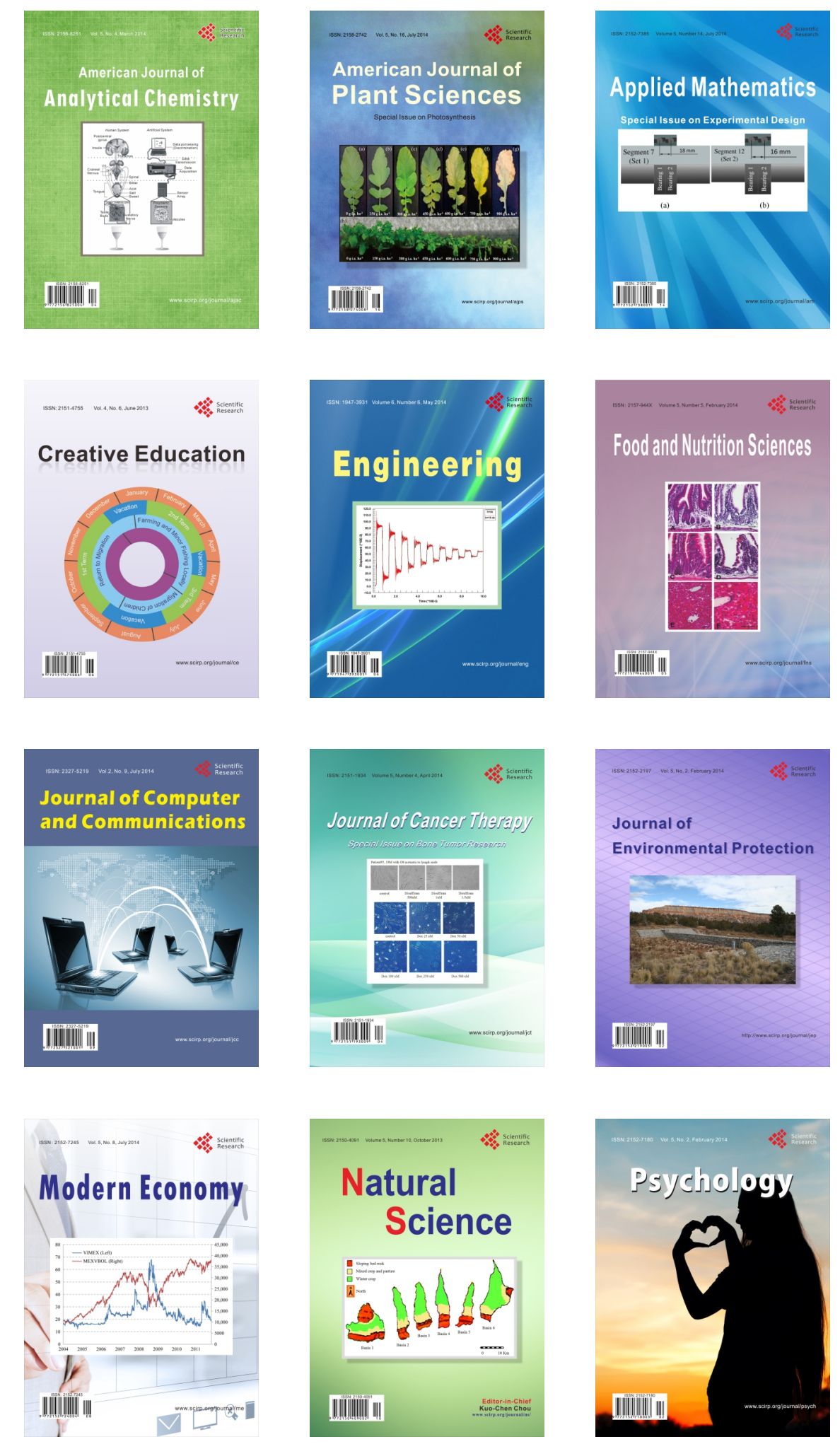